\title{
Motor intervention activities for children with autism spectrum disorders
}

Catama, Bryan V. $₫$

School of Teacher Education and Liberal Arts, Faculty of Professional Education Department, Saint Louis University, Baguio City, Philippines (chapsbryan12@gmail.com)

Calalang, Wielm Mae S.

School of Teacher Education and Liberal Arts, Saint Louis University, Baguio City, Philippines (calalngwielmmae@gmail.com)

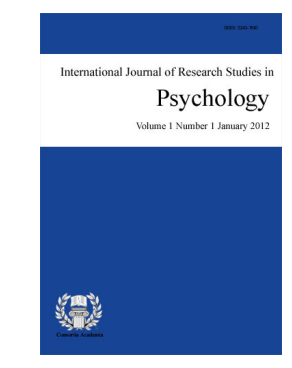

ISSN: 2243-7681 Online ISSN: 2243-769X

OPEN ACCESS

Cada, Renz Karlo D.

School of Teacher Education and Liberal Arts, Saint Louis University, Baguio City, Philippines (Renz.regz25@gmail.com)

Ballog, Angelica C.

School of Teacher Education and Liberal Arts, Saint Louis University, Baguio City, Philippines (angelballog19@gmail.com)

Batton, Kaylee B.

School of Teacher Education and Liberal Arts, Saint Louis University, Baguio City, Philippines (Leekay008@gmail.com)

Bigay, Ma. Lourdes R.

School of Teacher Education and Liberal Arts, Saint Louis University, Baguio City, Philippines (malourdesbigay@gmail.com)

Borje, Denice Jan J.

School of Teacher Education and Liberal Arts, Saint Louis University, Baguio City, Philippines (deniceborje1829@gmail.com)

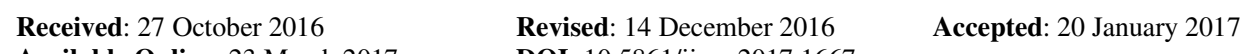

\section{Abstract}

One of the defining characteristics of children with Autism Spectrum Disorders is deficit in motor functioning. The necessity of intervention activities in improving the motor skills of children with ASD is greatly needed. Thus, this study explores extent of effectiveness of the gross and fine motor intervention activities that are used by twelve (12) Special Education (SPED) teachers who have a direct contact with those children with ASD in three (3) school-centers in Baguio City. A mixed method, both quantitative and qualitative, was used in gathering and interpreting the data of this research. It was found out that the extent of effectiveness on the use of gross motor intervention activities for children with ASD was effective, while the extent of effectiveness on the use of fine motor intervention activities for children with ASD was very effective.

Keywords: motor intervention; gross motor skills; fine motor skills; Autism Spectrum Disorders 


\section{Motor intervention activities for children with autism spectrum disorders}

\section{Introduction}

Motor impairments are part of the Autism Spectrum Disorders diagnosis, rather than a trait genetically carried in the family which entails that motor impairments are the core characteristic of the diagnosis (Hilton, Zhang, White, Klohr, \& Constantino, 2012). Evidently, motor abnormalities in ASD can be observed in infancy (Brian, Bryson, Garon, Roberts, Smith, Szatmari, \& Zwaigenbaum, 2008; Provost, Lopez, \& Heimerl, 2007; Teitelbaum, Teitelbaum, Nye, Fryman, \& Maurer, 1998; Ozonoff, Young, Goldring, Grelss-Hess, Herrera, Steele, \& Rogers, 2008) and are apparent throughout childhood and into adulthood (Fournier, Hass, Naik, Lodha, \& Cauraugh, 2010; Ming, Brimacombe, \& Wagner, 2007; Van Waelvelde, Oostra, Dewitte, Van Den Broeck, \& Jongmans, 2010). Children and adolescents with Asperger's Syndrome and high-functioning autism have delays or disorders in overall motor development, including locomotors and object control (Berkeley, Zittel, Pitney, \& Nichols, 2001).

Markedly, a number of different motor deficits have been observed using standardized test batteries and the prevalence of such deficits has been reported to be between $21 \%$ and $100 \%$ (Ghaziuddin, Butler, Tsai, \& Ghaziuddin, 1994; Green, Baird, Barnett, Henderson, Huber, \& Henderson, 2002; Manjiviona \& Prior, 1995; Miyahara, Tsujii, Hori, Nakanishi, Kageyama, \& Sugiyama, 1997; Pan, Tsai, \& Chu, 2009), highlighting that motor impairment is significant but potentially a variable aspect of ASD. Several researches exposed that compared to typically developing individuals (TDI), children and adolescents with Autism have greater in coordination (David, Baranek, Giuliani, Mercer, Poe, \& Thorpe, 2009), reduced grip strength (Hardan, Kilpatrick, Keshhavan, \& Minshew, 2003; Williams, Higgins, \& Brayne, 2005), and mixed results for motor speed with some studies reporting impaired motor speed (Takarae, Mishew, Luna, Krisky, \& Sweeney, 2004) and some reporting no significant differences (Hardan, Kilpatrick, Keshhavan, \& Minshew, 2003; Minshew \& Goldstein, 1998; Williams, Higgins, \& Brayne, n.d). These motor impairments lie within the vestibular system which is the sensory system that responds to accelerated and decelerated movement (Zachry, 2011). Motor skills and coordination in children with ASD is affected because of the abnormal vestibular responses and the difficulty to coordinate one's body (Baranek, 2002 as cited in Ozonoff, Young, Goldring, Grelss-Hess, Herrera, Steele, \& Rogers, 2008). Children with ASD are shown to have poor upper limb coordination during visual motor and manual dexterity tasks and poor lower limb coordination (Bhat, Landa, \& Galloway, 2011). Other specific motor impairments include manual control/writing, manual dexterity/coordination, ball skill, gait, balance, body coordination, strength and agility, praxis, imitation, postural stability, and speed (Hilton, 2011).

Furthermore, a well-designed retrospective study with a large sample identified fine motor delays in infants later diagnosed with ASDs. These delays were observed in a range of behaviors over the first and second years of life, including reaching, clapping, pointing, playing with blocks and puzzles, and turning doorknobs (Gernsbacher, Sauer, Geye, Schweigert, \& Hill Goldsmith, 2008). Infants who developed ASDs by the end of their second year showed gross and fine motor delays by 14 months (Landa \& Garrett-Mayer, 2006). Weakness in grip strength seems to be apparent from a young age for children with high functioning Autism and persists through adolescence and early adulthood. Although considered a simple motor skill, the importance of adequate grip strength cannot be overlooked. In general, grip strength is considered an objective measure of upper extremity functional integrity (Balogun, Akomolafe, \& Amusa, 1991). Fair grip strength is essential for independence in early childhood functional tasks (Amundson, 1995; Hager-Ross \& Rosblad, 2002) as well as in community-dwelling older adults (Hyatt, Whitelaw, Bhat, Scott, \& Maxwell, 1990). The particular character of their motor planning concerns; however, may depend on other functional considerations which have unique consequences on movement time optimization (Forti, Valli, Perego, Nobile, Crippa, \& Molteni, 2011).

Observably, children with ASD demonstrate a variety of behaviors which affect their ability to participate in 
their daily occupations. These behaviors show themselves by the tendency to impose rigidity on daily activities; habits and patterns of play; preoccupations with interests; and motor and sensory problems such as rocking, spinning, sensitivity to food or clothing, or a strong attachment to an object (Clark, Miller-Kuhaneck \& Watling, 2004 as cited in Miller-Kuhanek, 2004). Difficulties in motor skills are one of the common reasons of referrals for occupational therapy (Ozonoff et al., 2008).

Occupational therapy addresses barriers to the participation of an individual, group or community that may occur as a result of illness or disability and/or obstacles in the social, institutional, and/or physical environment (Canadian Association of Occupational Therapists [CAOT], 2002). The goal of occupational therapy interventions is to enable individuals to participate in everyday occupations. This may be achieved through a range of therapy approaches such as modification of tasks and/or the environment to match individuals' abilities, developing skills such as posture and coordination, or development of daily routines to facilitate adaptive behaviors (National Institute of Child Health and Development, 2005).

There are also other therapies for improving the motor skill of children with ASD such as the sensory integration therapy and physical therapy. Sensory integration therapy is one of the intervention techniques, and it is centered on improving sensory and motor abilities (Baranek, 2002 as cited in Schaaf, Benevides, Kelly, \& Mailloux-Maggio, 2012). This type of therapy is found to improve fine and gross motor skills as well as upper limb coordination (Hilton, 2011). Occupational therapists utilize various models of intervention when addressing motor deficits (Polatajko \& Cantin, 2010). These include sensory integration treatment, neurodevelopmental treatment (NDT), cognitive orientation to daily occupational performance (CO-OP) approach, perceptual motor training, strength training, and individual skill training. The use of visual aids, task analysis, applied behavioral analysis, and augmentative communication devices all support the work of occupational therapists with this specific population. Occupational therapists understand that the ability to perform meaningful activities is complex and is influenced by factors involving the person (such as an individual's physical or emotional ability), the environment (safety, supports available to carry out activity, accessibility) and the nature of the activity itself (size and texture of objects) (Whiteford, Townsend, Stanton \& Canadian Association of Occupational Therapists, 2002).

Recognizing the results of the many and varied research studies that one of the defining characteristics of children with ASD is a deficit in motor functioning, the researchers decided to conduct this study. The necessity of intervention activities in improving the motor skills of children with ASD is greatly needed. Further, while extensive research has been done on various therapies and motor invention skills of children with ASD, very few particularly dealt with motor intervention activities given by special education classroom teachers to their learners with ASD. It is noted that SPED classroom teachers have the direct contact with their learners in the day-to-day teaching and learning process. Also, a survey of existing literature shows that studies on this topic are limited in the country and the city of Baguio. With these, and with the aim of highlighting and improving the motor skills of children with ASD with proper motor intervention activities by the SPED classroom teachers, this study was conceptualized.

\subsection{Purpose of the Research}

This research study determined the motor intervention activities given by SPED classroom teachers to children with ASD in three (3) SPED school-centers in Baguio City, Philippines. Specifically, the study sought answers to the following questions:

$>\quad$ What are the classroom motor intervention activities given by SPED teachers in improving the gross and fine motor skills of children with ASD?

$>\quad$ What is the extent of effectiveness of the gross and fine motor intervention activities given by SPED teachers in improving the motor skills of children with ASD? 
The findings of this study will serve as the basis for understanding more of the motor conditions of children with ASD which requires proper motor intervention activities. Further, results of this study could benefit an additional knowledge and skills for the SPED teachers to be more creative in the four walls of the classroom in the implementation of the IEP successfully most importantly on the motor development of children with ASD. Knowing and understanding the reasons why motor intervention activities are important for the development of the motor skills of children with ASD will allow principals/administrators to enhance and continue searching for other motor intervention skills that would be very helpful for these children. Likewise, a clear and thorough understanding of those motor intervention skills will enable school principals/administrators to further support not only for the motor development of children with ASD but also in total support of the parents as number one partners of the school in the proper implementation of the program.

\section{Literature Review}

\subsection{Autism Spectrum Disorders}

Autism Spectrum Disorders (ASD) is a pervasive developmental disorder (PDD) which involves delay in many areas of development (Coucouvanis, Hallas, \& Farley, 2008). It is characterized by difficulties in social interaction and communication, as well as by repetitive, restricted interests, and behaviors (American Psychiatric Association, 1994). These patterns become apparent in the first few years of life and are lifelong challenges (Schieve, Rice, Boyle, Visser, \& Blumberg, 2006). Besides, studies have shown that ASD is also associated with greater clumsiness, motor coordination, abnormalities, postural instability, and poor performance on standardized testing of motor functioning (Fournier, Hass, Naik, Lodha, \& Cauraugh, 2010).

\subsection{Gross and Fine Motor Skills}

Motor skills are affected in the motor functioning of children with ASD. These motor skills include the gross and fine motor skills. Gross motor skills are the fundamental skills necessary for movement competence and considered the basic building blocks for more complex motor skill development (Clark \& Humphrey, 2002; Robinson \& Goodway, 2009). It is the goal-directed movement patterns that allow children to move through space and respond in a suitable way to a variety of stimuli using larger musculatures (Liu, 2012; Haywood \& Getchell, 2009 as cited in Liu, Hamilton, Davis, \& Garhy, 2014). On the other hand, fine motor skills are collective skills and activities that involve using hands and finger (Weil \& Amundson, 1994). Fine motor skills are typically developed in a reasonably consistent and predictable pattern in the early years of childhood (Exner, 2001).

\subsection{Motor Intervention Activities}

Motor intervention activities are set of activities in improving the motor performances of children with ASD such as coordination problems, poor balance, clumsiness, marked delays in achieving developmental motor milestones, or in the acquisition of basic motor skills. Whilst, an acquisition of good motor skills is important for a range of everyday abilities such as communication and language development (Gernsbacher, Sauer, Geye, Schweigert, \& Hill Goldsmith, 2008), playing and interacting with others (Clearfield, 2011), mental imagery (Williams, Thomas, Maruff, \& Wilson, 2008) and perception (Blaesi \& Wilson 2010; Eskenazi , Grosjean, Humphreys, \& Knoblich, 2009; Wilson \& Knoblich, 2005), it is likely that atypical development of motor control can have far reaching consequences on development (Leary \& Hill, 1996).

\section{Methodology}

This research study used the mixed research method because the researchers intentionally integrated or combined the quantitative and qualitative data rather than keeping them separated. The basic concept is that integration leads to maximizing the strengths of the quantitative and qualitative data and minimizing their 
weaknesses. This idea of integration separated current views of mixed methods from older perspectives in which researchers collected both forms of data but kept them separated or casually combined them rather than using systematic, integrative procedures (Creswell \& Plano Clark, 2011). A checklist questionnaire was used to gather information from the respondents on how they assess the extent of effectiveness of gross and fine motor activities for children with ASD. Most of these motor activities were taken from Janet W. Lerner's discussion on motor and perceptual development (Lerner, 2003). A focused group interview discussion was also used to follow-up or to verify the respondents' answers and supplemented the different data which was obtained by the researchers. The focused group interview is a good way of gathering together people from similar backgrounds or experiences to discuss a specific topic of interest. The participants were guided by a group facilitator who introduced the topic for discussion and helps the group to participate in a lively and natural discussion amongst themselves (Stewart, Shamdasani, \& Rook, 2007).

\subsection{Participants and Setting}

The locales of the study were three SPED school-centers that catered to children with special needs most especially those with ASD in Baguio City, Philippines. These SPED school-centers were chosen because they offer special education classes where teachers are graduates of Special Education course. Also, these SPED school-centers have the most number of learners with Autism Spectrum Disorders and are located within the city limits. The respondents of this study were twelve (12) SPED teachers who have direct contacts with children with ASD who have motor problems.

\subsection{Materials and Procedures}

The research instrument used in this study was composed of two parts: Part 1 comprised the list of gross and motor intervention activities for children with ASD, and Part 2 contained the extent of effectiveness of the motor intervention activities for children with ASD. Before the actual administration of the questionnaire to the targeted population, the researcher asked the approval of the Dean of the School of Teacher Education, Saint Louis University through a letter which was noted by the research coordinator and by the faculty research promoter. Permission was also sought from the School Principals or coordinators in charge of the three (3) SPED institutions involved in the study. The questionnaire was administered personally by the researchers to each of the respondents. Respondents were guaranteed the confidentiality of information. The researchers retrieved the questionnaire personally. To answer problem Number 1 regarding the classroom motor intervention activities given by SPED teachers in improving the gross and fine motor skills of children with ASD, frequency counts, and percentages were computed. To answer problem Number 2 regarding the extent of effectiveness of the gross and fine motor intervention activities in improving the motor skills of children with ASD, frequency counts, percentages, and means was computed. Each item in the extent of effectiveness of the gross and fine motor intervention activities for children with ASD had four choices with the following responses and was determined and interpreted using the following scale:

\section{Table 1}

Statistical Interpretation on the Extents of Effectiveness of the Gross and Fine Motor Intervention Activities for Children with ASD

\begin{tabular}{lll}
\hline Weighted Mean & Extent of Effectiveness & \multicolumn{1}{c}{ Description } \\
\hline $3.25-4.00$ & Very Effective & $\begin{array}{l}\text { Motor intervention activities had a major effect on the } \\
\text { improvement of motor skills of children with ASD } \\
\text { Motor intervention activities had an effect on the improvement } \\
\text { of motor skills of children with ASD } \\
\text { Motor intervention activities had a minor effect on the } \\
\text { improvement of motor skills of children with ASD } \\
\text { Motor intervention activities had no effect on the improvement } \\
\text { of the motor skills of children with ASD }\end{array}$ \\
\hline
\end{tabular}




\section{Results and Discussion}

\subsection{Gross Motor Intervention Activities for Children with ASD}

Presented in Table 2 are the respondents' extents of effectiveness in improving the gross motor skills of children with ASD. It is evident from Table 2 that catching objects (balls, etc.) gained the highest weighted mean of 3.50, followed by throwing objects (balls, etc.) with a weighted mean of 3.40, and bouncing (trampoline, bedsprings, mattress, etc.) with a weighted mean of 3.33 which are interpreted as very effective which means that the gross motor intervention activities had a major effect on the improvement in the gross motor skills of children with ASD.

\section{Table 2}

Extents of effectiveness in improving the gross motor skills of children with ASD

\begin{tabular}{lcc}
\hline Gross Motor Intervention Activities & Weighted Mean & Qualitative Interpretation \\
\hline Forward walk & 3.20 & Effective \\
Backward walk & 3.00 & Effective \\
Sideways walk & 3.00 & Effective \\
Variations walk & 3.13 & Effective \\
Animal walk & 2.22 & Slightly effective \\
Cross-pattern walk & 2.33 & Slightly effective \\
Line walks & 3.20 & Effective \\
Hopscotch games & 2.70 & Effective \\
Hoop games & 2.50 & Slightly effective \\
Rope skills & 2.70 & Effective \\
Throwing objects (balls, etc.) & 3.40 & Very effective \\
Catching objects (balls, etc.) & 3.50 & Very effective \\
\multicolumn{1}{c}{ Average Weighted Mean } & 2.95 & Effective \\
\hline
\end{tabular}

According to Rain (2006).), the use of balls for catching and throwing, and the use of a trampoline for bouncing are effective ways to strengthen muscles while developing valuable skills for children with ASD. This corroborated with the study of Bennet, Gorassini, and Prochazka (1994) stating that the use of balls for throwing and catching positively affects the intrinsic muscle stiffness, reflexes, and higher order responses of muscles. Moreover, playing ball for catching and throwing develops hand-eye coordination, foot-eye coordination, and control of larger muscles for children with ASD. In the long run, children with ASD also learn to track objects as they move and judge distance when they roll, throw, hit, and kick balls of various sizes (Rain, 2006).

During the focus group discussion the respondents mentioned that as children with ASD play with balls, particularly throwing and catching balls, they find enjoyment and satisfaction. Such engrossment to ball game activities by children with ASD, the respondents affirmed that they performed it routinely. They do it before they start the lesson to prepare the child. Most of the time the teachers incorporate it with their subject matter to gain the child with ASD's attention. Consequently, the child with ASD will throw tantrums if they are deprived of playing such activity. Furthermore, due to the established routine of playing ball game activities, the respondents observed that the balance and posture of the child with ASD are improving.

"At first we observed that some of our pupils, as they enter the classroom, they immediately look for the ball and start playing with it. Sometimes it is very hard for us to get it from them because we are afraid that the child might start throwing a tantrum, though, we set our rules that the child can only play within 15 minutes before the class starts and 15 minutes before they are picked up by their caregivers. At some point, there are instances that they hit the teacher-in-charged once they are not given a chance to play with the ball. We make this activity as part of our motivation for the child to be focused and participative during class discussion. When the child participates, we allow time for playing as his reward. We observed that there's an 
Motor intervention activities for children with autism spectrum disorders

improvement in his posture and balance when they're standing and walking." - [Female SPED

Teacher, 34 years old]

Meanwhile, the bouncing motion of trampoline being the king of gross motor activities for children with ASD offers excellent sensory input in alleviating sensory overload and anxiety in many cases (Rain, n.d). On the other hand, it helps children with ASD develop their proprioceptive system that is the receptors from muscles and joints inform and give body awareness and provide information on how to move innately (Kuhaneck \& Glennon, 2001; Blanche \& Schaaf, 2001 as cited in Schaff \& Benevides 2012). Furthermore, trampoline activities encourage muscle development, strengthen bones, reinforce joints, and improve balance and foster kinaesthetic awareness. Also, bouncing on a trampoline stimulates almost every sense, leading to a more involved interaction amongst children with ASD and the outside environment. Thus, as children with ASD jump on a trampoline, there is the integration of their body's systems in one simple movement which provides an unparalleled vestibular motion feedback that is the body's response to the movement as it is traveling through space ("Trampoline Therapy", 2011).

During the focus group discussion with the respondents, they emphasized that bouncing activities (trampoline, bedsprings, mattress, etc.) promote socialization with other children. As observed by the respondents, children with ASD together with their classmates tend to race with each other to the play area due to the excitement. They were observed to find pleasure and contentment as evident to their engagement to such activity. Also, it was revealed by the respondents that the bouncing activities (trampoline, bedsprings, mattress, etc.) are not only implemented in school but also performed in their home. Meaning, there is a continuation of the activity both at home and at school which results to further progress of the gross motor skill of the child. Additionally, it was claimed by the respondents that flexibility and coordination are enhanced every time they play.

"Every time they see the trampoline, their mood changes. We observed that their facial expression is very different compared when they are not playing on the trampoline. Often, they laugh out loud and bounce at the trampoline even if they are already exhausted. Sometimes, I get irritated with their noise but knowing that they are enjoying and there is the development of their flexibility and coordination in standing and walking; I just let them continue to play. In fact, I am happy because I observed that socialization is seen in them. There are times when I talked to some parents, and they've shared that their child continuously jumps in their bed at home." [Male SPED Teacher, 28 years old]

Moreover, animal walk has the least weighted mean of 2.22 , followed by cross-pattern walk with a weighted mean of 2.33, and hoop games with a weighted mean of 2.5 which are interpreted as slightly effective which means that the gross motor intervention activities had a minor effect on the improvement of motor skills of children with ASD. Evidently, these three gross motor intervention activities are the most complex activities for children with ASD. Before they can master such skills, they have to master first some other basic or fundamental locomotor skills. Payne and Isaacs (2008) as cited in Saracho, \& Spodek, (2012) revealed new investigations that before a child can proceed to the major gross motor milestones, one must have to undergo the smaller sub-steps toward achievement of those gross motor abilities. After children with ASD begin to take their first steps, they gradually become more consistent in their stride length, thereby adopting a characteristic of adult walking (Looper, Wu, Barroso, Ulrich, \& Ulrich, 2006). They also learn a variety of breaking behaviors when they are walking down slopes (Gill, Adolph, \& Vereijken, 2009). Mastery of these skills is directly related to the frequency and quality of experiences they have playing on playgrounds and in classroom and homes (Damon, \& Lerner, 2006).

Likewise, during the focus group discussion, the respondents said that they seldom use such activities due to the complexity and difficulty of executing it. As to the animal walk activity, they mentioned that it is an activity that requires not only movement but also critical thinking to accomplish. This goes with the nature of the child 
with ASD having a poor comprehension skill. Similarly, the respondents said that cross-pattern walk activity necessitates a rigorous instruction to follow; thus, a step-by-step procedure must be considered. Prompting and modeling are essential for the child with ASD to participate. Correspondingly, hoop game activities are often used by the respondents due to lack of materials, limited space in the classroom, and it is causing children with ASD to hurt one another physically.

"We often use animal walk and cross pattern activities because we consider the level of comprehension of our students. And we all know that it takes a step-by-step giving of the instruction, prompting and modeling for them to follow. Sometimes the whole class period is not enough to finish the activity. While for the hoop game activities though we like the students to do it our materials are not enough. And, the students use them to hurt each other that's why our materials are easily broken, and we need to provide a new one. Aside from that, our classroom space is not enough that's why it's easy to hurt each other.” - [Male SPED Teacher, 37 years old]

Overall, the respondents had an effective result in the gross motor intervention activities with a 2.99 average weighted mean which means that the gross motor intervention activities had an effect on the improvement of gross motor skills of children with ASD. This implies that the use of gross motor intervention activities for children with ASD are important due to the fact that they serve as building blocks or foundation of movements for more complex and specialized skills required for children with ASD to competently and confidently play different games, sports, and recreational activities given at school and in the community all throughout their lives (Department of Education Western Australia, 2013). Also, gross motor intervention activities are effective for developing postural control in standing position, increased the ability to utilize an optimal energy transfer from one gait cycle to another and increased success and coordination of eye-arm movements (Bugnariu, De Weerd, Young, Longnecker, Garver, Van Loon, \& Patterson, 2013). Likewise, it has the potential to improve the overall development of a child if utilized properly in the participation in physical and other motor activities (Goff \& Folmar, 2016).

\subsection{Fine Motor Intervention Activities for Children with ASD}

Presented in Table 3 are the respondents' extents of effectiveness in improving the fine motor skills of children with ASD. It is evident from the table that scribbling gained a weighted mean of 3.80 followed by coloring (coloring books, readiness books, etc.)with a weighted mean of 3.60, and block designs with a weighted mean of 3.40 which are interpreted as very effective which means that the fine motor intervention activities had a major effect on the improvement of the fine motor skills of children with ASD.

\section{Table 3}

Extents of effectiveness in improving the fine motor skills of children with ASD

\begin{tabular}{|c|c|c|}
\hline Fine Motor Intervention Activities & Weighted Mean & Qualitative Interpretation \\
\hline Tracing (lines, pictures, designs, letters, numbers, etc.) & 3.40 & Very effective \\
\hline Water control (carrying and pouring water) & 3.33 & Very effective \\
\hline Cutting with scissors & 3.33 & Very effective \\
\hline Lacing & 3.25 & Effective \\
\hline Coloring (coloring books, readiness books, etc.) & 3.60 & Very effective \\
\hline Clipping clothespins & 3.30 & Very effective \\
\hline Copying designs (geometric designs, etc.) & 2.80 & Effective \\
\hline Paper folding or origami & 3.30 & Very effective \\
\hline Dot to dot connecting & 3.30 & Very effective \\
\hline Beads designs & 3.30 & Very effective \\
\hline Block designs & 3.40 & Very effective \\
\hline Playing cards & 2.20 & Effective \\
\hline Scribbling & 3.80 & Very effective \\
\hline Average Weighted Mean & 3.26 & Very Effective \\
\hline
\end{tabular}


Scribbling and coloring (coloring books, readiness books, etc.) are said to be one of those important pre-writing activities that help to develop the fine motor skills of all children in general. These two pre-writing skills are essentials for a child to be able to develop the ability to hold and move a pencil or crayon fluently and therefore produce legible writing (Buttfield, 2016).

Specifically, scribbling is the tangled matrix where drawing and writing begin. Children's scribbles act as relevant visual attention stimuli, they are evidence of basic, underlying, dyadic, back-and-forth, oscillatory, organizational brain mechanisms, and are the beginning of the drawing, reading, and writing (Sheridan, 2002). This is supported by Levick (1998), Winner (1982), and Lowenfeld and Brittain (1970) (as cited in Palencia, 2012) when they narrated that through scribbling children begin to discover their limbs as part of their body that they have control over, they will similarly begin to recognize their ability to move and control objects. This is reflected as they become more focused on their scribbles. At this stage, they are developing their hand-eye coordination as well as their visual control. For this reason, it is important to give them the freedom to repeat as many times as they need without intervening with new materials or drawing lessons (Palencia, 2012).

During the focus group discussion, the respondents mentioned that during scribbling activities the students showed their creativity in a non-formal way. Evidently, they freely expressed it by drawing a different type of lines such as loops, curves, straight, zigzag, etc. Moreover, according to the respondents, the child with ASD enjoys and is good to watch them doing the said activity. This is shown when they scribble using different crayons and happily making representations out of their outputs. Also, the respondents observed that their students' patience is lengthened; this is evident when the students sit for a longer time than the usual. Also, the respondents were so confident in saying that their learners with ASD's hand-eye coordination are enhanced when they repeatedly scribble while finding out what they wanted to draw. This activity's materials are readily available that increased its times of implementation. Space is not a problem, anywhere a child may be they can scribble with just a paper and a pen the activity may be done.

"We all know that before the child learns to write the alphabets, they start scribbling. Often, when they spot crayons they'll start scribbling anywhere they are, they use the walls, door or blank spaces as their canvas. Through this scribbles, we can see the creativity of our students. Sometimes they even create a story to what they've drawn. Not just because it is part of their activity, but also they're having fun. Because we always use this activity, we noticed that while the students think of what they're going to write in their papers their hand and eye coordination is improved. Compared to other activities, this activity's materials are always available, space in also not a problem because anywhere they are they can do the activity." - [Female SPED Teacher, 42 years old]

On the other hand, coloring helps children develop good finger grip. It provides an opportunity to practice holding a pencil the correct way and aids in developing fine motor muscles in their hands, fingers, and wrist (Davis, 2015). Likewise, aside from the positive effect of coloring to the fine motor skills of children with ASD, it also stimulates the creativity, improves focus and eye coordination, adheres to boundaries, structure and spatial awareness, and improves confidence and self-esteem of children with ASD (Dena, 2015).

During the focus group discussion, the respondents mentioned that while coloring, the children are observed to be enthusiastic when the teacher instructs them to get ready for their coloring tools. The children start to jump and clap to show excitement on the activity most especially in coloring animal patterns, shapes, and cartoon characters. Also, as they do the activity for so many times they gradually improve their ability to use their hands skillfully.

"The children's reaction to coloring is the same as their reaction when they are doing the scribbling activity. They are very happy when they see the crayons and other coloring materials, some are even jumping for joy and some are clapping their hands. Happiness is very visible when the activity is coloring. They like to color pictures they're familiar with like animals, 
shapes, and sometimes their favorite cartoon character. You can see that because we always do this activity. Some colors with accuracy which mean that they're improving."- [Female SPED Teacher, 25 years old]

Block activities for children with ASD such as sorting and building blocks help develop and improve control on the finger and muscle strengths, as well as encouraging creative play. Block activities such as carrying blocks, piling blocks, connecting blocks, and making elaborate constructions refine the fine motor skills of children by building complex structures that require balance, a steady hand, and hand-eye coordination (Extension Foundation, 2015). In particular, the use of LEGO bricks come in a vast range of shapes and sizes, which smaller hands need learn how to assemble and take apart. These small twists and turns of hands, fingers, and arms promote coordination and dexterity which children need for handwriting, crafts, and independent dressing. On the other hand, through the manipulation of LEGO bricks children with ASD learn about applying differential pressure; some bricks need small amounts of pressure when building while others require a great deal (Carr, 2015).

During the focus group discussion, the respondents said that playing blocks activate the child with ASD's eagerness to participate in the activity. Due to various colors and shapes, most of these children are fascinated to manipulate them. They make several patterns, designs, figures, and models. That is why their grip to certain objects is enriched. This is evident every time they create a bigger figure as they move it to one place to another. More than that, the respondents observed that children with ASD are little by little becoming inventive and innovative as evident when they transform simple block materials into different figures.

\begin{abstract}
"As we all know, block designs has different colors and sizes, right? Because of these most of the children were fascinated with it so they are very excited to manipulate it and we can see that it is an activity where we can immediately get the attention of the child, and they are very eager to participate. Due to the different sizes of the blocks, we often see that the children's grip were enhanced that they can build taller and bigger figures such as towers, trees, and other simple objects that show how creative they can be. We also ask them to carry some of their work so we can see if they can do it without our help." - [Male SPED Teacher, 35 years old]
\end{abstract}

Furthermore, playing cards has the least weighted mean of 2.2, followed by copying designs (geometric designs, etc.) with weighted mean of 2.8, and lacing with a weighted mean of 3.25 which are interpreted as slightly effective which means that the fine motor intervention activities had minor effect on the improvement of fine motor skills of children with ASD. It is noted that these four fine motor intervention activities are difficult for some children, especially when combined with all the other things that are needed for school skills, such as balance, muscle tone, hand stability, and muscle strength midline crossing and visual and auditory processing simultaneously. It's hard to imagine, but it takes a lot of effort and attention combining all of these things and then remembers to use the fingers muscles accurately (Howard, n.d).

According to Hogan (n.d), though playing a variety of cards seems enjoyable for the first exposure of the child with ASD due to its designs and colors, it is frustrating to work on as time goes by for it is harder to accomplish. This leads to confusion because playing cards have one or more symbols of the same kind on the face but the identical design on the reverse (Collins, 2014). Similarly, copying designs need a laborious effort to accomplish that makes a child with ASD avoid participating due to short attention span. According to Miller (2013), copying designs is to copy a mere increasingly detailed pattern, to copy the picture given as close as the original. It is difficult for children to work on because it requires memorization and analyzing skills. When instructions are given the child verbally analyzes before copying, while nonverbal requires memorization skills to be able for them to copy the design presented which gives the child hard time in doing the activity (Quinn, 2010). In the same way, lacing is much more challenging because it needs holes and strings which make it difficult to execute for children with ASD (McClure, 2012). The cords are drawn through eyelets or around hooks to draw together two edges (Chen, 2010). 
The complexity of these three fine motor activities are evident when the respondents said in the focus group discussion that it is observed that when the child with ASD lose patience, they easily get disturbed, throw tantrums, make unnecessary movements, toss their school materials, and they even hurt their classmates if not their teachers. This leads to waste of time and difficulty to continue with the next activity. Instead, the respondents ended up calming and pacifying the child to focus and cooperate with other scheduled activities of the day.

\footnotetext{
"It's not that we don't let the students do the activity. We tried for sometimes, but the result is always the same. Some students throw tantrums, some throw their materials anywhere, some hurt other classmates or if not they hurt us. Because they can't accomplish the activity immediately their patience is shortened we have to calm them down, and it takes too much time to do it, that's why we can't continue with the activities. The time is being wasted because of consoling them." [Female SPED Teacher, 28 years old]
}

Overall, the respondents had a very effective result in the fine motor intervention activities with a 3.26 average weighted mean which means that the fine motor intervention activities had a great effect on the enhancement of fine motor skills of children with ASD. This implies that the implementation of fine motor intervention activities for children with ASD developed a greater sense of self-confidence and demonstrated improved skill levels (Brook, Wagenfeld, \&Thompson, 2016). Many children show significant improvement in their fine motor skills when given greater exposure to and practice creative fine motor activities (Dankert, Davies, \& Gavin, 2003; Cameron, Brock, Murrah, Bell, Worzalla, Grissmer, \& Morrison, 2012). Also, the improvement of fine motor skills in children will permit them to do a variety of significant functional tasks (Zimmer \& Desch, 2012). Likewise, fine motor skills activities are the best way to ensure proper development and practice of fine motor skills to promote the most functional use of a child's hands ("Sensory Processing", n.d.).

\section{Conclusion and Recommendations}

Motor intervention activities are important in the development of the gross and fine motor skills of children with ASD's such as their balance and coordination, flexibility, agility, ocular-motor coordination, and dexterity in handwriting. Other than that, additional skills can be developed when using such intervention activities like social, creativity, and innovative skills. In this study, the researchers found out that the intervention activities for gross motor skills and fine motor skills had an effect on children with ASD. Particularly, it was found out that the extent of effectiveness of the gross motor intervention activities for children with ASD was effective, while the fine motor intervention activities for children with ASD resulted in being very effective. These were all evident based on the result of the survey questionnaire and was verified during the focus group interview discussion with the respondents. Specifically, the gross motor intervention activities that resulted in being very effective were "catching objects," "throwing objects, and "bouncing" which lead to further improvement of the children with ASD's motor functioning skills. As for the fine motor intervention activities, the top three most effective intervention done by teachers were "scribbling," "coloring," and "block designs" which caused a positive effect on the child with ASD's fine motor functioning such as dexterity in handwriting and enhanced ability to use their hands skillfully. Based on the findings, it is then recommended that continues use of these motor intervention activities (gross motor and fine motor intervention activities) be sustained to further enhance the positive effect on the motor skills of children with ASD. Such use of these motor intervention activities should not only be limited at school but also at home. Moreover, it is strongly recommended that future researchers shall also venture with other disabilities which these motor intervention activities could be applied to find out if the extent of the effect is similar to children with ASD. Such would be a big help in the field of Special Education.

\section{References}

Abdel Karim, A. E., \& Mohammed, A. H. (2015). Effectiveness of sensory integration program in motor skills in children with autism. Egyptian Journal of Medical Human Genetics, 16(4), 375-380. 
Catama, B. V., Calalang, W. M. S., Cada, R. K. D., Ballog, A. C., Batton, K. B., Bigay, M. L. R., \& Borje, D. J. J.

https://doi.org/10.1016/j.ejmhg.2014.12.008

American Psychiatric Association (APA). (2000). Diagnostic and statistical manual of mental disorders:

DSM-IV-TR. Washington, DC: American Psychiatric Association.

Amundson, S. J. (1995). Evaluation tool of children's handwriting: ETCH examiner's manual. Homer, AK: OT Kids.

Baker, M. (2015). How LEGO supports child development. Retrieved from http://www.welovebricks.com/how-lego-supports-child-development/

Balogun, J. A., Akomolafe, C. T., \& Amusa, L. O. (1991). Grip strength: Effects of testing posture and elbow position. Archives of Physical Medicine and Rehabilitation, 72, 280-283.

Baranek, G. T. (2002). Efficacy of sensory and motor interventions for children with autism. Journal of Autism and Developmental Disorders, 32(5), 397-422. https://doi.org/10.1023/A:1020541906063

Bennett, D. J., Gorassini, M., \& Prochazka, A. (1994). Catching a ball: contributions of intrinsic muscle stiffness, reflexes, and higher order responses. Canadian Journal of Physiology and Pharmacology, 72(5), 525-534. https://doi.org/10.1139/y94-076

Berkeley, S. L., Zittel, L. L., Pitney, L. V., \& Nichols, S. E. (2001). Locomotor and object control skills of children diagnosed with autism. Adapted Physical Activity Quarterly, 18(4), 405-416. https://doi.org/10.1123/apaq.18.4.405

Bhat, A., Landa, R., \& Galloway, J. (2011).Current perspectives on motor functioning in infants,children, and adults with autism spectrum disorders. Physical Therapy, 91(7), 1116-1129. https://doi.org/10.2522/ptj.20100294

Blaesi, S., \& Wilson, M. (2010). The mirror reflects both ways: Action influences perception of others. Brain and Cognition, 72(2), 306-309. https://doi.org/10.1016/j.bandc.2009.10.001

Blanche, E.I. \& Schaaf, R.C. (2001). Proprioception: A cornerstone of sensory integration intervention. In S.S. Roley, E. Blanche, \& R. Schaaf, (Eds.) Understanding the nature of sensory integration with diverse populations (pp. 109-124). San Antonio, TX: Therapy Skill Builders.

Brian, J., Bryson, S., Garon, N., Roberts, W., Smith, I., Szatmari, P., \& Zwaigenbaum, L. (2008).Clinical assessment of autism in high-risk 18-month-olds. Autism, 12(5), 433-456. https://doi.org/10.1177/1362361308094500

Brook, G., Wagenfeld, A., \& Thompson, C. (2016). Fine motor development and early school performance. Samford Valley, Australia: Australian Academic Press Group, Ltd.

Bugnariu, N., De Weerd, C., Young, C., Longnecker, R., Garver, C., Van Loon, E., \& Patterson, R. M. (2013). Motor function in children with autism spectrum disorders. In the International Conference on Virtual Rehabilitation (pp. 51-56). https://doi.org/10.1109/icvr.2013.6662080

Buttfield, J. (2016). Writing readiness (pre-writing) skills. Retrieved from http://www.childdevelopment.com.au/images/Resources/area_of_concern_pdfs/Prewriting_Skills.pdf

Cameron, C. E., Brock, L. L., Murrah, W. M., Bell, L. H., Worzalla, S. L., Grissmer, D., \& Morrison, F. J. (2012). Fine motor skills and executive function both contribute to kindergarten achievement. Child Development, 83(4), 1229-1244. https://doi.org/10.1111/j.1467-8624.2012.01768.x

Canadian Association of Occupational Therapists. (2002). Enabling occupation: An occupational therapy perspective (Rev. ed.). Ottawa, ON: CAOT Publications ACE.

Canadian Association of Occupational Therapists. (2005). Membership statistics. Retrieved from http://www.caot.ca

Chen, X. (2010). An English dictionary with $A B$ index and frequency. UK.

Clark, J. E., \& Humphrey, J. H. (2002). The mountain of motor development: A metaphor. Retrieved from https://www.researchgate.net/publication/273403393_The_mountain_of_motor_development_A_met aphor

Clearfield, M. W. (2011). Learning to walk changes infants' social interactions. Infant Behavior and Development, 34(1), 15-25. https://doi.org/10.1016/j.infbeh.2010.04.008

Collins English dictionary (12th ed.). (2014). Australia: HarperCollins Publishers.

Coucouvanis, J. R., Hallas, D., \& Farley, J. N. (2013).Autism spectrum disorder. Child and Adolescent Behavioral Health, 238-261. https://doi.org/10.1002/9781118704660.ch13

Creswell, J. W., \& Plano, C. V. (2011). Designing and conducting mixed methods research. Los Angeles: SAGE Publications.

Damon, W., \& Lerner, R. M. (2006). Handbook of child psychology (6th ed.). Hoboken, NJ: John Wiley \& Sons.

Dankert, H. L., Davies, P. L., \& Gavin, W. J. (2003). Occupational therapy effects on visual-motor skills in preschool children. The American Journal of Occupational Therapy, 57(5), 542-549. 
Motor intervention activities for children with autism spectrum disorders

https://doi.org/10.5014/ajot.57.5.542

David, F. J., Baranek, G. T., Giuliani, C. A., Mercer, V. S., Poe, M. D., \& Thorpe, D. E. (2009). A pilot study: Coordination of precision grip in children and adolescents with high functioning autism. Pediatric Physical Therapy, 21(2), 205-211. https://doi.org/10.1097/PEP.0b013e3181a3afc2

Davis, J. (2015). Benefits of colouring in activities. Retrieved from http://www.learning4kids.net/2015/06/22/benefits-of-colouring-in-activities/

Dena, P. (2015). Ten benefits of coloring pages for kids' psychology and development. Retrieved from http://www.colorpsychology.org/10-benefits-of-coloring-pages-for-kids-psychology-and-developmen t/

Department of Education WA. (2013). Fundamental movement skills: Book 1 - Learning, teaching, and assessment. Australia, WA: Author.

Eskenazi, T., Grosjean, M., Humphreys, G. W., \& Knoblich, G. (2009). The role of motor simulation in action perception: a neuropsychological case study. Psychological Research, 73(4), 477-485. https://doi.org/10.1007/s00426-009-0231-5

Exner, M. (2001). Fine motor development and early school performance. Retrieved from http://www.fingergym.info/downloads/Finemotordevpp1-4.pdf

Extension Foundation (2015). The block center in child care. Retrieved from http://articles.extension.org/pages/67335/the-block-center-in-child-care

Forti, S., Valli, A., Perego, P., Nobile, M., Crippa, A., \& Molteni, M. (2011). Motor planning and control in autism: A kinematic analysis of preschool children. Research in Autism Spectrum Disorders, 5, 834-842. https://doi.org/10.1016/j.rasd.2010.09.013

Fournier, K. A., Hass, C. J., Naik, S. K., Lodha, N., \& Cauraugh, J. H. (2010). Motor coordination in autism spectrum disorders: A synthesis and meta-analysis. Journal of Autism and Developmental Disorders, 40(10), 1227-1240. https://doi.org/10.1007/s10803-010-0981-3

Gernsbacher, M. A., Sauer, E. A., Geye, H. M., Schweigert, E. K., \& Goldsmith, H. H. (2008). Infant and toddler oral- and manual-motor skills predict later speech fluency in autism. Journal of Child Psychology Psychiatry, 49(1), 43-50. https://doi.org/10.1111/j.1469-7610.2007.01820.x

Ghaziuddin, M., Butler, E., Tsai, L., \& Ghaziuddin, N. (2008). Is clumsiness a marker for Asperger syndrome? Journal of Intellectual Disability Research, 38(5), 519-527. https://doi.org/10.1111/j.1365-2788.1994.tb00440.x

Gill, S. V., Adolph, K. E., \& Vereijken, B. (2009). Change in action: how infants learn to walk down slopes. Developmental Science, 12(6), 888-902. https://doi.org/10.1111/j.1467-7687.2009.00828.x

Goff, J., \& Folmar, E. (2016). The effectiveness of a group gross motor intervention on preschoolers with autism spectrum disorder. Retrieved from

http://www.northeastern.edu/rise/presentations/the-effectiveness-of-a-group-gross-motor-intervention -on-preschoolers-www.northeastern.edu/rise/presentations/the-effectiveness-of-a-group-gross-motor-i ntervention-on-preschoolers-with-autism-spectrum-disorder/with-autism-spectrum-disorder/

Gowen, E., \& Hamilton, A. (2012). Motor abilities in autism: A review using computational context. Journal of Autism and Developmental Disorders, 43(2), 323-344. https://doi.org/10.1007/s10803-012-1574-0

Green, D., Baird, G., Barnett, A. L., Henderson, L., Huber, J., \& Henderson, S. E. (2002). The severity and nature of motor impairment in Asperger's syndrome: a comparison with specific developmental disorder of motor function. Journal of Child Psychology and Psychiatry, 43(5), 655-668. https://doi.org/10.1111/1469-7610.00054

Häger-Ross, C., \& Rösblad, B. (2002). Norms for grip strength in children aged 4-16 years. Acta Paediatric, 91(6), 617-625. https://doi.org/10.1111/j.1651-2227.2002.tb03290.x

Hardan, A. Y., Kilpatrick, M., Keshavan, M. S., \& Minshew, N. J. (2003). Motor performance and anatomic magnetic resonance imaging (MRI) of the basal ganglia in autism. Journal of Child Neurology, 18(5), 317-324. https://doi.org/10.1177/08830738030180050801

Haywood, K., \& Getchell, N. (2009). Lifespan motor development (5th ed.). Champaign, IL: Human Kinetics.

Hilton, C. L. (2011). Sensory processing and motor issues in autism spectrum disorders. In the International handbook of autism and pervasive developmental disorders (pp. 175-193). New York, NY US: Springer Science Business Media. https://doi.org/10.1007/978-1-4419-8065-6_11

Hilton, C. L., Zhang, Y., Whilte, M. R., Klohr, C. L., \& Constantino, J. (2012). Motor impairment in sibling pairs concordant and discordant for autism spectrum disorders. Autism, 16(4), 430-441. https://doi.org/10.1177/1362361311423018

Hogan, K. (n.d.). Nonverbal thinking, communication, imitation, and play skills with some things to remember. Retrieved from http://teacch.com/communication-approaches-2/nonverbal-thinking-communication-imitation-and-pla 
y-skills-with-some-things-to-remember

Howard, A. (n.d.). Sensory history of autism. Retrieved from http://www.therapyfoundationsforeducation.co.uk/Documents/Article\%20on\%20Autism.pdf

Hyatt, R. H., Whitelaw, M. N., Bhat, A., Scott, S., \& Maxwell, J. D. (1990). Association of muscle strength with functional status of elderly people. Age Ageing, 19(5), 330-336. https://doi.org/10.1093/ageing/19.5.330

Kuhaneck, H. M., \& Watling, R. (2015). Occupational therapy: Meeting the needs of families of people with autism spectrum disorder. American Journal of Occupational Therapy, 69(5). https://doi.org/10.5014/ajot.2015.019562

Landa, R., \& Garrett-Mayer, E. (2006). Development in infants with autism spectrum disorders: a prospective study. The Journal of Child Psychology and Psychiatry, 47(6), 629-638. https://doi.org/10.1111/j.1469-7610.2006.01531.x

Leary, M. R., \& Hill, D. A. (1996). Moving on: Autism and movement disturbance. Mental Retardation, 43(1), 39-53.

Lerner, J. W. (2003). Learning disabilities: Theories, diagnosis, and teaching strategies. Boston: Houghton Mifflin.

Levick, M. F. (1998). See what I'm saying: What children tell us through their art. Dubuque, IA: Islewest Pub.

Liu, T. (2012). Motor milestone development in young children with autism spectrum disorders: An exploratory study. Educational Psychology in Practice, 28(3), 315-326. https://doi.org/10.1080/02667363.2012.684340

Liu, T., Hamilton, M., Davis, L., \& Garhy, S. E. (2014). Gross motor performance by children with autism spectrum disorder and typically developing children on TGMD-2. Journal of Child and Adolescent Behaviour, 2(123). https://doi.org/10.4172/2375-4494.1000123

Looper, J., Wu, J., Barroso, R. A., Ulrich, D., \& Ulrich, B. D. (2006). Changes in step variability of new walkers with typical development and with down syndrome. Journal of Motor Behavior, 38(5), 367-372. https://doi.org/10.3200/JMBR.38.5.367-372

Lowenfeld, V., \&Brittain, W. L. (1970). Creative and mental growth (5th ed.). New York, NY: The Macmillan Company.

McClure, S. (2012). Focus on fine motor skills-lacing. Retrieved from http://happybrownhouse.com/focus-on-fine-motor-skills-lacing/

Miller, D. C. (2013). Essentials of school neuropsychological assessment. Hoboken, NJ: John Wiley \& Sons.

Miller-Kuhaneck, H. (2004). Autism: A comprehensive occupational therapy approach. Bethesda, MD: American Occupational Therapy Association.

Ming, X., Brimacombe, M., \& Wagner, G. C. (2016). Prevalence of motor impairment in autism spectrum disorders - Autism web forum. Retrieved from http://www.autismweb.com/forum/viewtopic.php?t=13012

Minshew, N. J., \& Goldstein, G. (1998). Autism as a disorder of complex information processing. Mental Retardation and Developmental Disabilities Research Review, 4, 129-136. https://doi.org/10.1002/(SICI)1098-2779(1998)4:2<129::AID-MRDD10>3.0.CO;2-X

Miyahara M., Tsujii M., Hori M., Nakanishi K., Kageyama H., \& Sugiyama T. (1997). Brief report: Motor incoordination in children with Asperger syndrome and learning disabilities. Journal of Autism and Developmental Disorders, 27(5), 595-603. https://doi.org/10.1023/A:1025834211548

National Institute of Child Health and Development. (2005). Autism overview: What we know. Retrieved from http://www.fcbha.org/PDF/What_We_Know_About_Autism.pdf

Ozonoff S., Williams B. J., \& Landa R. (2005) Parental report of the early development of children with regressive autism: the delays plus-regression phenotype. Autism 9, 461-486. https://doi.org/10.1177/1362361305057880

Ozonoff, S., Young, G.S., Goldring, S., Greiss-Hess, L., Herrera, A.M., Steele, J., Macari, S., Hepburn, S., \& Rogers, S.J. (2008). Gross motor development, movement abnormalities, and early identification of autism. Journal of Autism and Developmental Disorder 38, 644-656. https://doi.org/10.1007/s10803-007-0430-0

Palencia, M. S. (2012, April 16). The importance of scribbling to childhood development [Web blog post]. Retrieved from http://magdalenaspalencia.blogspot.com/2012/04/importance-of-scribbling-to-childhood.html

Pan, C. Y., Tsai, C. L., \& Chu, C. H. (2009). Fundamental movement skills in children diagnosed with autism spectrum disorders and attention deficit hyperactivity disorder. Journal of Autism and Developmental Disorders 39, 1694-1705. https://doi.org/10.1007/s10803-009-0813-5

Polatajko, H. J., \& Cantin, N. (2010). Exploring the effectiveness of occupational therapy interventions, other 
Motor intervention activities for children with autism spectrum disorders

than the sensory integration approach, with children and adolescents experiencing difficulty processing and integrating sensory information. American Journal of Occupational Therapy, 64(3), 415-429. https://doi.org/10.5014/ajot.2010.09072

Provost, B., Lopez, B. R., \& Heimerl, S. (2007). A comparison of motor delays in young children: Autism spectrum disorder, developmental delay, and developmental concerns. Journal of Autism and Developmental Disorders, 37(2), 321-328. https://doi.org/10.1007/s10803-006-0170-6

Quinn, K. (2010). Testing for kindergarten: Simple strategies to help your child ace the tests for: public school placement, private school admissions, gifted program qualification. New York: Fireside/Simon \& Schuster.

Rain, E. (2006). Ten gross motor activities for autistic children. Retrieved from http://autism.lovetoknow.com/Ten_Gross_Motor_Activities_for_Autistic_Children

Robinson, L. E., \& Goodway, J. D. (2009). Instructional climates in preschool children who are at-risk. Part I: Object-control skill development. Research Quarterly for Exercise and Sport, 80, 533-542. https://doi.org/10.1080/02701367.2009.10599591

Saracho, O. N., \& Spodek, B. (2012). Handbook of research on the education of young children (3rd ed.). New York: Routledge/Taylor and Francis Group.

Schaaf, R., Benevides, T., Kelly, D., \& Mailloux-Maggio, Z. (2012). Occupational therapy and sensory integration for children with autism: A feasibility, safety, acceptability, and fidelity study. Autism, 16(3), 321-327. https://doi.org/10.1177/1362361311435157

Schieve, L. A., Rice, C., Boyle, C., Visser, S. N., \& Blymberg, S. J. (2006). Mental health in the United States: Parental report of diagnosed autism in children aged 4-17 years, United States, 2003-2004. Retrieved from http://www.cdc.gov/MMWR/preview/mmwrhtml/mm5517a3.htm

Sensory Processing. (n.d). Sensory processing disorder (SPD). Retrieved from http://www.sensory-processing-disorder.com

Sheridan, S. R. (2002). The neurological significance of children's drawing: The scribble hypothesis. Retrieved from http://www.drawingwriting.com/uploads/2/6/1/5/26150872/scribble_hypothesis.pdf

Stewart, D. W., Shamdasani, P. N., \& Rook, D. W. (2007). Focus groups: Theory and practice. Thousand Oaks: SAGE Publications. https://doi.org/10.4135/9781412991841

Takarae, Y., Mishew, N. J., Luna, B., Krisky, C. M., \& Sweeney, J. A. (2004). Pursuit eye movement deficits in autism. Brain, 127, 2584-2594. https://doi.org/10.1093/brain/awh307

Teitelbaum, P., Teitelbaum, O., Nye, J., Fryman, J., \& Maurer, R. G. (1998). Movement analysis in infancy may be useful for early diagnosis of autism. Proceedings of the National Academy of Sciences, 95,

13982-13987. https://doi.org/10.1073/pnas.95.23.13982

Townsend, E., Stanton, S., \& Canadian Association of Occupational Therapists. (2002). Enabling occupation: An occupational therapy perspective. Ottawa: Canadian Association of Occupational Therapists.

Trampoline Therapy. (2011). Trampoline therapy for special needs children. Retrieved from https://www.vulyplay.com/blog/trampolines-and-special-needs-children

Van Waelvelde, H. V., Oostra, A., Dewitte, G., Van Den Broeck, V., \& Jongmans, M. J. (2010). Stability of motor problems in young children with or at risk of autism spectrum disorders, ADHD, and or developmental coordination disorder. Developmental Medicine \& Child Neurology, 52(8), 174-178. https://doi.org/10.1111/j.1469-8749.2009.03606.x

Weil, M. J., \& Cunningham Amundson, S. J. (1994). Relationship Between Visuomotor and Handwriting Skills of Children in Kindergarten. American Journal of Occupational Therapy, 48, 982-988. https://doi.org/10.5014/ajot.48.11.982

Whiteford, G., Townsend, E., \& Hockin, C. (2000). Reflections on a renaissance of occupation. Canadian Journal of Occupational Therapy, 67(1), 61-69. https://doi.org/10.1177/000841740006700109

Williams, J. G., Higgins, J. P., \& Brayne, C. E. (2005). Systematic review of prevalence studies of autism spectrum disorders. Archives of Disease in Childhood, 91(1), 8-15. https://doi.org/10.1136/adc.2004.062083

Williams, J., Thomas, P. R., Maruff, P., \& Wilson, P. H. (2008). The link between motor impairment level and motor imagery ability in children with developmental coordination disorder. Human Movement Science, 27(2), 270-285. https://doi.org/10.1016/j.humov.2008.02.008

Wilson, M., \& Knoblich, G. (2005). The case for motor involvement in perceiving conspecifics. Psychological Bulletin, 131(3), 460-473. https://doi.org/10.1037/0033-2909.131.3.460

Wimmer, H., \& Perner, J. (1983). Beliefs about beliefs: representation and constraining function of wrong beliefs in young children's understanding of deception. Cognition, 13(1), 103-128. https://doi.org/10.1016/0010-0277(83)90004-5

Zachary, A. (2011). Tactile, vestibular and proprioceptive senses. Retrieved from 
Catama, B. V., Calalang, W. M. S., Cada, R. K. D., Ballog, A. C., Batton, K. B., Bigay, M. L. R., \& Borje, D. J. J.

http://cherringtonsawers.com/tactile-vestibular-and-proprioceptive-senses.html

Zimmer, M., \& Desch, L. (2012). Sensory integration therapies for children with developmental and behavioral disorders. The American Academy of Pediatrics, 129(6), 1186-1189. 